\title{
Study of Free-Ranging and Stray Dog Population in Omsk
}

\author{
Marat T. Makenov*a and Boris Yu. Kassal ${ }^{\mathrm{b}}$ \\ ${ }^{a}$ Omsk Research Institute of Natural Focal Infection \\ 7 Prospect Mira, Omsk, 644080, Russia \\ ${ }^{b}$ Omsk State Pedagogical University \\ 14 Nab. Tuhachevskogo Str., Omsk, 644043, Russia
}

Received 07.05.2013, received in revised form 30.06.2013, accepted 15.02.2014

The characteristics of free-ranging and stray dog population in Omsk City (Russia) were examined. The first section contains estimates of the population density in different urban areas. The average population density is 69 animals $/ \mathrm{km}^{2}$. Section 2 shows the sex ratio in dog population. The predominance of male over females has been registered with the overall sex ratio (male/female) equal 1:0,79. The section 3 characterizes the litter size for stray dogs. The average litter size is 4,3 pups per female.

Keywords: free-ranging dogs, stray dogs, density, litter size, sex ratio.

Исследование популяции

свободноживущих собак г. Омска

\author{
М.Т. Макенов ${ }^{\mathbf{a}}$, Б.Ю. Кассал ${ }^{\mathbf{6}}$ \\ ${ }^{a}$ Омский НИИ природно-очаговых инфекиий Роспотребнадзора \\ Россия, 644080, Омск, пр. Мира, 7 \\ ${ }^{6}$ Омский государственный педагогический университет \\ Россия, 644043, Омск, ул. Набережная Тухачевского, 14
}

В работе дана оченка плотности популящии свободноживущих собак г. Омска в разных типах городской среды, оченка численности популящии. Средняя плотность популяции составила 69 ос/км². Изучена половая структура популяции. Во всех типах городской среды, кроме жилой одноэтажной застройки, соотношение полов составляет примерно 1:1, в жилой

(C) Siberian Federal University. All rights reserved

* Corresponding author E-mail address: mmakenov@gmail.com 
одноэтажной зоне численно преобладают кобели (61\%). Охарактеризованы размеры выводков свободноживущих собак - в среднем 4,3 щенка (для возраста щенков 1-1,5 мес.).

Ключевые слова: бродячие собаки, плотность популяиии, половой состав, размер выводков.

\section{Введение}

Совместное существование собак и человека в пределах урбанизированных территорий создает целый ряд проблем (Рахманов, 2002; Березина, 2012; Макенов, Михайлова, 2013). Среди них особое значение имеют вопросы распространения собаками зооантропонозов и проявление прямой агрессии по отношению к человеку. Для решения так называемой проблемы бродячих животных необходим комплексный экологический подход, одной из первых задач является оценка численности и структуры популяции свободноживущих собак.

Цель данной работы: изучить особенности экологии популяции свободноживущих собак г. Омска - их численность и плотность популяции, охарактеризовать половой состав, оценить размеры выводков свободноживущих собак.

\section{Материалы и методы}

Выделение экологических групп собак

В пределах крупных городов России сосуществуют собаки разных экологических групп (Березина, 2002; Рахманов, 2002; Седова, 2007), количество и состав этих групп варьирует в зависимости от подходов и целей исследований. В самом общем виде можно выделить три крупные группы:

- собаки владельческие;

- собаки полувольного содержания;

- собаки бесхозяйные.

Собаки владельческие - это особи, имеющие хозяина, который их кормит, выгуливает, контролирует размножение, поведение.
Породные собаки этой группы размножаются преимущественно только в пределах породы и репродуктивно изолированы от собак других пород.

Собаки полувольного содержания - это особи, имеющие хозяина, который их кормит (но не всегда), имеющие возможность свободно покидать территорию домохозяйства (квартиры, дома, приусадебного участка) или предприятия без сопровождения человека. Эти собаки могут свободно реализовывать своё поведение, контактировать с бесхозяйными собаками и участвовать в размножении.

Собаки бесхозяйные - это особи, не имеющие хозяина и живущие на улицах города.

Все указанные экологические группы собак образуют крупную метапопуляцию города, которая состоит из нескольких популяций, разделённых репродуктивными барьерами. Собаки бесхозяйные и собаки полувольного содержания образуют единую популяцию, для её обозначения мы используем термин «свободноживущие собаки»; владельческих собак мы к этой популяции не относим, т.к. они, как правило, репродуктивно изолированы. В предыдущих работах мы использовали термин «собаки-парии» (Макенов, 2007), однако после дискуссий с коллегами мы пришли к мнению, что этот термин характеризует больше филогенетическую группу собак (Боголюбский, 1959), нежели экологическую. Поэтому, чтобы не вносить путаницу, мы решили отказаться от данного термина. Наиболее удачным нам представляется термин 
«свободноживущие собаки», предложенный Е.С. Березиной (2012).

Определение численности популяции

Учёты численности популяции проводили в феврале-апреле 2005 г. Для определения численности и плотности популяции свободноживущих собак была разработана схема исследования:

1. Разделение городской среды на зоныбиотопы.

2. Выбор учётных площадок в каждой зоне-биотопе.

3. Выбор контрольного участка в каждой зоне-биотопе.

4. Проведение учётов в каждой зонебиотопе.

4.1. Пеший однократный учёт собак на учётных площадках.

4.2. Накопительный пятикратный учёт собак на контрольном участке (пеший).

5. Определение полноты учёта по данным контрольного участка.

6. Коррекция недоучёта на учётных площадках вне контрольного участка.

7. Определение плотности популяции и экстраполяция скорректированных данных.

Территория города в зависимости от характера застройки была разделена на пять зон-биотопов: жилая многоэтажная, жилая одноэтажная, промышленная, садовоогородная и рекреационная (парки, скверы). В каждой зоне-биотопе случайным образом было выбрано несколько учётных площадок с известной площадью (табл. 1), границы выбранных участков старались приурочить к границам микрорайонов, жилых кварталов крупным оживлённым дорогам, пустырям, озёрам и т.п. Примерно половину площадок выбирали ближе к центру города, а вторую половину - ближе к окраине. Площадь исследованных участков задавали исходя из следующих предпосылок:

- участок должен быть не меньше $0,5 \mathrm{\kappa M}^{2}$;

- суммарная площадь исследованных участков в каждой зоне-биотопе должна быть не менее 5 \% от общей площади зоны-биотопа.

Промышленную зону-биотоп мы разделили на слитную и дробную. Слитная промзона - это территория крупных предприятий с большой площадью (Омский нефтеперерабатывающий завод, ПО «Полёт», ПО им. Баранова и др). Это огороженные глухим забором охраняемые территории, к которым у нас не было доступа. Как правило, собаки на таких предприятиях приурочены к проходным, столовым, отдельным цехам. Численность собак на таких предприятиях мы определяли, опрашивая сторожей, сотрудников. Дробная промзона представлена территорией, на которой расположено несколько некрупных предприятий. В каждом из них может жить своя стая собак. В дробной промзоне между отдельными предприятиями есть свободное пространство (улицы, пустыри, проезды), к которым есть свободный доступ и можно проводить учёт.

В рекреационную зону мы объединили парки и крупные скверы города. При проведении учётов мы обследовали все городские парки, приравнивая границы учётной площадки к границам парков, поэтому площадь обследованной территории по данной зоне-биотопу оказалась очень высока (табл. 1).

На каждой площадке проводили тотальный учёт собак, учёту подлежали все встреченные особи без сопровождения человека и без ошейника. Учёт вели в утренние часы пешком, тщательно прочёсывая площадку, 
Таблица 1. Объем выборочной совокупности при исследовании плотности популяции собак г. Омска

\begin{tabular}{|c|c|c|c|c|c|}
\hline \multirow{2}{*}{ Зона-биотоп } & \multirow{2}{*}{ 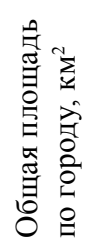 } & \multirow{2}{*}{ 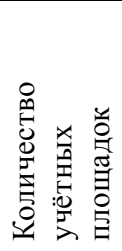 } & \multicolumn{2}{|c|}{$\begin{array}{c}\text { Площадь } \\
\text { учётных площадок, км² }\end{array}$} & \multirow{2}{*}{ 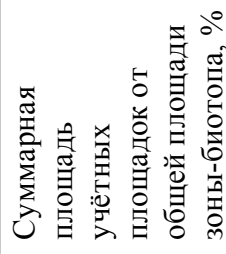 } \\
\hline & & & Средняя & Общая & \\
\hline Жилая одноэтажная & 37,1 & 5 & 0,7 & 3,3 & 9 \\
\hline Жилая многоэтажная & 46,6 & 6 & 0,6 & 3,6 & 7,8 \\
\hline Промышленная & 48,8 & 10 & 0,1 & 1,2 & 2,4 \\
\hline Садово-огородная & 65,8 & 7 & 0,6 & 4,2 & 6,4 \\
\hline Рекреационная & 5,1 & 4 & 1,1 & 4,3 & 84,3 \\
\hline Всего & 203,4 & 32 & 0,6 & 16,6 & 8,2 \\
\hline
\end{tabular}

проходили через все дворы, улицы, заглядывали в каждый закоулок, кустарник и т.д. все открытые и свободные от построек места должны были быть осмотрены в непосредственной близости.

Для оценки недоучета использовали метод коррекции по данным контрольного участка (Челинцев, 2000). Он заключался в том, что в пределах зоны-биотопа выделялся контрольный участок, где помимо учета, проведенного по обычной технологии, определяли полное количество всех обитающих здесь свободноживущих собак. Для этого нами был использован метод последовательного пятикратного учета (Поярков и др., 2011; Челинцев, 2000). Внутри каждой зоны-биотопа, независимо от сплошных учетов, выделялся контрольный участок, где в течение пяти дней подряд проводился сплошной накопительный учет собак с индивидуальным распознаванием каждой особи. Для того чтобы повысить вероятность обнаружения собак, учёты проводили в разное время дня (утром, днём, вечером) в дни с благоприятными погодными условиям. Все учёты проводил один учётчик, на каждую встреченную собаку с помощью диктофона составлялся подробный устный портрет с описанием ключевых морфологических при- знаков (форма ушей, шерсти, хвоста, особенности окраса), указывалось место встречи. По окончании учёта диктограмы вносили в базу данных, это позволило исключить ошибку при индивидуальном распознавании особи.

\section{Оиченка полноты учета}

и коррекция полевых данных

Использованные нами формулы для необходимых расчётов были предложены Н.Г. Челинцевым (2000).

1. Определение полного количества свободноживущих собак на контрольном участке по данным пятикратных учетов. Для этого сначала определяли полноту учёта:

$$
\begin{aligned}
& \widetilde{\varphi}_{0}=1-\prod_{i=1}^{m}\left(1-\widetilde{p}_{i}\right) ; \quad \tilde{p}_{i}=\frac{n_{i d}}{n_{-i}}, \\
& e\left(\tilde{\varphi}_{0}\right)=\sqrt{\frac{\left(1-\widetilde{\varphi}_{0}\right)^{2}}{\widetilde{\varphi}_{0}{ }^{2}} \cdot \sum_{i=1}^{m} \frac{\tilde{p}_{i}}{n_{-i}\left(1-\tilde{p}_{i}\right)}},
\end{aligned}
$$

где $\widetilde{\varphi}_{0}$ - оценка общей полноты учета при всех $\boldsymbol{m}$ обследованиях; $\widetilde{p}_{i}-$ полнота $\boldsymbol{i}$-го учета; $n_{-i}$ число собак, обнаруженных на заданной территории во время всех остальных учетов (без $\boldsymbol{i}$-го учета); $n_{i d}$ - число собак, обнаруженных во время $\boldsymbol{i}$-го учета повторно из числа собак $n_{-i}$; 
$e\left(\widetilde{\varphi}_{0}\right)$ - относительная статистическая ошибка оценки совместной полноты всех учетов.

Затем производили коррекцию недоучета собак на контрольном участке:

$$
\begin{aligned}
& \tilde{N}_{c}=\frac{n}{\widetilde{\varphi}_{0}}, \\
& e\left(\widetilde{N}_{c}\right)=\sqrt{\frac{1-\widetilde{\varphi}_{0}}{n}+\frac{\left(1-\widetilde{\varphi}_{0}\right)^{2}}{\widetilde{\varphi}_{0}{ }^{2}} \cdot \sum_{i=1}^{m} \frac{\widetilde{p}_{i}}{n_{-i}\left(1-\widetilde{p}_{i}\right)}},
\end{aligned}
$$

где $\widetilde{N}_{c}$ - оценка полного (скорректированного на недоучет) числа собак, находящихся на контрольном участке; $n$ - общее число собак, обнаруженных на заданной территории во время всех $m$ учетов; $e\left(\widetilde{N}_{c}\right)-$ относительная статистическая ошибка оценки полной, скорректированной на недоучет численности животных на исследуемой территории.

2. Коррекция недоучета всей выборочной совокупности зоны-биотопа по данным контрольного участка.

$\tilde{\varphi}=\frac{n_{c}}{\widetilde{N}_{c}}$,

$e(\widetilde{\varphi})=\sqrt{\left(1-\frac{n_{c}}{\widetilde{N}_{c}}\right) \cdot \frac{1}{n_{c}}}$,

$\tilde{N}_{w}=\frac{n_{w}}{\widetilde{\varphi}}$

$e\left(\widetilde{N}_{w}\right)=\sqrt{\left(1-\frac{n_{c}}{\widetilde{N}_{c}}\right) \cdot\left(\frac{1}{n_{c}}+\frac{1}{n_{w}}\right)}$,

где $\widetilde{\varphi}-$ полнота учета на контрольном участке; $n_{c}$ - число собак, обнаруженных на контрольном участке при проведении основного учета (при однократном обследовании); $\widetilde{N}_{c}$ - полное число собак, выявленное при специальном обследовании на контрольном участке (скорректированное после пятикратного обследования); $e(\widetilde{\varphi})$ - относительная статистическая ошибка оценки полноты учета; $\widetilde{N}_{w}$ - скорректированная оценка полного числа собак, находящихся на заданной территории вне контрольного участка; $n_{w}-$ число собак, обнаруженных на заданной территории вне контрольного участка во время основного учета; $e\left(\widetilde{N}_{w}\right)$ - относительная статистическая ошибка оценки полного числа собак.

Полученные по формуле (7), скорректированные на возможный недоучет, значения численности собак на всех площадках выборочной совокупности использовали для определения плотности популяции на данных участках.

\section{Определение плотности популяции}

и экстраполячия

скорректированных данных

Оценка средней плотности популяции на всей территории данного биотопа по расчетным значениям плотности на $\boldsymbol{h}$ выборочных площадках, имеющих разные размеры $q_{k}$, была найдена по средней взвешенной:

$$
\widetilde{D}=\sum_{k=1}^{h} D_{k} w_{k}, \quad D_{k}=\frac{n_{k}}{q_{k}}, \quad \sum_{k=1}^{h} w_{k}=1
$$

$$
e(\widetilde{D})=e(\tilde{N})=\sqrt{\frac{1}{h(h-1)} \cdot \sum_{k=1}^{h}\left(\frac{D_{k}}{\widetilde{D}}-1\right)^{2}}
$$

где: $D_{k}$ - плотность популяции на $k$-й площадке; $n_{k}$ - полное (скорректированное на недоучет) число собак на $k$-й площадке; $q_{k}-$ площадь $k$-й площадки; $w_{k}$ - оптимальный весовой коэффициент, который был определен из условия минимума дисперсии оценки плотности и равен $w_{k}=\frac{1}{h} ; e(\widetilde{D})-$ относительная статистическая ошибка оценки плотности и численности населения собак на заданной территории. 
Общая численность популяции собак, а также средневзвешенная оценка плотности населения на всей территории г. Омска определялись по формулам:

$$
\begin{aligned}
& \tilde{N}_{O}=\sum_{j=1}^{g} \tilde{N}_{j}, \\
& \widetilde{D}_{O}=\frac{1}{Q_{O}} \sum_{j} \tilde{N}_{j},
\end{aligned}
$$

$$
e\left(\widetilde{D}_{O}\right)=e\left(\widetilde{N}_{O}\right)=\frac{1}{\widetilde{N}_{O}} \sqrt{\sum_{j} e^{2}\left(\widetilde{N}_{j}\right) \widetilde{N}_{j}^{2}},
$$

где $\tilde{N}_{O}$ - общая численность популяции; $\widetilde{N}_{j}$ - численность собак в $j$-м биотопе; $g$ - количество биотопов; $\widetilde{D}_{O}-$ средневзвешенная плотность населения на всей исследуемой территории; $Q_{O}$ - площадь всей исследуемой территории.

Так как общая площадь выборочных площадок в рекреационной зоне-биотопе сравнима с площадью всей зоны-биотопа, при расчете статистической ошибки оценки плотности популяции в формулу (10) был введен коррек-

тирующий множитель $1-\frac{q}{Q}$, учитывающий площадь выборки по сравнению с площадью территории (Челинцев, 2000).

Помимо точечных оценок численности были произведены и интервальные оценки численности для каждой зоны-биотопа, а также общей численности популяции. Интервальная оценка численности при уровне доверия 95 \% определялась по формулам:

$$
\begin{aligned}
& \left.\widetilde{N}_{U}=\widetilde{N} \exp \left\{1,64 \widetilde{\sigma}-0,5 \widetilde{\sigma}^{2}\right\}, \quad \widetilde{\sigma}=\sqrt{\ln \left[1+e^{2}(\widetilde{N})\right.}\right], \\
& \left.\widetilde{N}_{L}=\widetilde{N} \exp \left\{-1,64 \widetilde{\sigma}-0,5 \widetilde{\sigma}^{2}\right\}, \quad \widetilde{\sigma}=\sqrt{\ln \left[1+e^{2}(\widetilde{N})\right.}\right], \\
& \left.\widetilde{N}_{U 2}=\widetilde{N} \exp \left\{1,96 \widetilde{\sigma}-0,5 \widetilde{\sigma}^{2}\right\}, \quad \widetilde{\sigma}=\sqrt{\ln \left[1+e^{2}(\widetilde{N})\right.}\right],
\end{aligned}
$$

$$
\widetilde{N}_{L 2}=\widetilde{N} \exp \left\{-1,96 \widetilde{\sigma}-0,5 \widetilde{\sigma}^{2}\right\}, \quad \widetilde{\sigma}=\sqrt{\ln \left[1+e^{2}(\widetilde{N})\right]},
$$

где $\widetilde{N}_{U}-$ односторонний верхний доверительный интервал; $\widetilde{N}_{L}$ - односторонний нижний доверительный интервал; $\widetilde{N}_{U 2}-$ двусторонний верхний доверительный интервал; $\widetilde{N}_{L 2}$ - двусторонний нижний доверительный интервал.

Изучение численности популяции г. Омска проводили для выделенных зонбиотопов, общая площадь которых соста-

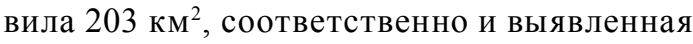
численность популяции свободноживущих собак включает особей, обитающих на данной площади. Оставшаяся часть территории в пределах административных границ города, не охваченная рассматриваемыми зонами-биотопами, представляет собой остатки негородских экосистем (луга, березовые колки), расположенных по окраинам города и непосредственно не примыкающих к застроенным территориям. В данных биотопах были проведены отдельные учеты в мае 2005 г. В результате этих учетов были выявлены единичные встречи собак, следов их постоянного пребывания (днёвки стай, логова, тропы и т.д.) обнаружено не было, что послужило основанием для исключения данных территорий из основного ареала популяции свободноживущих собак г. Омска.

Суммарная площадь учётных площадок в промышленной зоне-биотопе составила 2,4 \% от общей площади зоны-биотопа, столь низкое значение обусловлено тем, что данная зона представлена огороженными охраняемыми территориями и свободный доступ к ним отсутствует (табл. 1). При определении численности выявленная средняя плотность населения экстраполировалась не на всю площадь промышленной зоны-биотопа, а только на ее дробную часть. Для слитной части чис- 
ленность определяли отдельно для каждого предприятия.

Из-за отсутствия свободного доступа к территории не удалось также провести пятикратные учеты в промышленной и садовоогородной зонах-биотопах. В связи с этим средняя взвешенная плотность населения в этих зонах-биотопах дана без коррекции на возможный недоучет. Однако следует отметить, что учётные данные с большинства площадок садово-огородной и промышленной зон-биотопов соотносились с опросами местных сторожей, опекунов собак, что сводило возможный недоучет к минимуму. В остальных зонах-биотопах коррекция недоучета проводилась по данным контрольного участка.

\section{Анализ половой структуры популяции}

У всех встреченных собак определяли пол, возраст (щенок - взрослая особь) и принадлежность к группе, если таковая имелась. Анализ соотношения полов проводили с помощью биномиального теста (binomial test).

\section{Оценка размера выводка}

Работа по изучению размера выводка свободноживущих собак велась с 2002 по 2006 гг. Мы исследовали постоянные стаи собак: изучали их состав, особенности поведения особей в группе, днёвки, логова. Размер выводков устанавливали путем подсчета щенков в логове или возле него, а также, если удавалось, проводили дополнительный опрос опекунов. Для анализа использовали данные о выводках с щенками не старше 1-1,5 месяцев. Сведения о размере выводка заносили в таблицу только в том случае, если удавалось установить полное число щенков в выводке на момент наблюдения. Всего за весь период наблюдений были получены данные о размере 78 выводков.

\section{Результаты}

Численность и плотность популящ̧ии

Анализ данных контрольного участка показал, что используемый метод учета дает максимальный недоучет в зоне-биотопе жилой одноэтажной застройки, где значение $\tilde{\varphi}$ составило всего 0,45 (табл. 2). Другими словами, учетчик встречает только 45 \% собак, обитающих на учетной площадке, остальные 55 \% недоступны для наблюдения. Принимая во внимание особенности проектирования кварталов жилой одноэтажной застройки, можно утверждать, что бо́льшая часть собак данной зоны-биотопа являются по статусу собаками полувольного содержания. То есть они закреплены за каким-либо двором, где живет их хозяин, но при этом собака содержится на свободном выгуле. Это позволяет ей пребывать на огороженной территории приусадебного участка, при этом она выпадает из поля зрения учетчика, что и снижает полноту учета. В рекреационной и жилой многоэтажной зонах-биотопах применяемый метод учета более эффективен и позволяет учесть 88 и $78 \%$ всех особей соответственно.

Плотность популяции свободноживущих собак значительно варьировала в зависимости от зоны-биотопа (табл. 3). Относительно высокая средняя плотность населения была зафиксирована в зоне-биотопе жилой одноэтажной застройки - 116,2ос/км². Столь высокое значение плотности в совокупности с выявленным низким показателем полноты учета обусловлено, по-видимому, тем, что бо́льшая часть собак в данной зоне-биотопе являются собаками полувольного содержания.

Максимальное значение средней плотности популяции свободноживущих собак зафиксировано в промышленной зонебиотопе - 126,2 ос/км². Столь высокое значение плотности населения собак в дроб- 
Таблица 2. Данные контрольного участка при исследовании популяции свободноживущих собак г. Омска, 2005 г.

\begin{tabular}{|c|c|c|c|c|c|c|c|}
\hline \multirow[t]{2}{*}{ Зона-биотоп* } & \multirow{2}{*}{$\begin{array}{c}\text { Число особей, } \\
\text { обнаруженных при } \\
\text { однократном обходе } \\
\text { участка, ос. }\end{array}$} & \multicolumn{2}{|c|}{$\begin{array}{l}\text { Оценка полноты } \\
\text { 5-кратного учета }\end{array}$} & \multicolumn{2}{|c|}{$\begin{array}{c}\text { Скорректированное } \\
\text { число особей } \\
\text { на контрольном } \\
\text { участке, ос. } \\
\end{array}$} & \multicolumn{2}{|c|}{$\begin{array}{c}\text { Оценка полноть } \\
\text { учета на } \\
\text { контрольном } \\
\text { участке } \\
\end{array}$} \\
\hline & & $\tilde{\varphi}_{0}$ & $e\left(\tilde{\varphi}_{0}\right)$ & $\tilde{N}_{c}$ & $e\left(\tilde{N}_{c}\right)$ & $\tilde{\varphi}$ & $e(\widetilde{\varphi})$ \\
\hline $\begin{array}{l}\text { Жилая } \\
\text { одноэтажная }\end{array}$ & 19 & 0,81 & 0,05 & 42 & 0,09 & 0,45 & 0,17 \\
\hline $\begin{array}{l}\text { Жилая } \\
\text { многоэтажная }\end{array}$ & 25 & 0,97 & 0,01 & 32 & 0,03 & 0,78 & 0,09 \\
\hline Рекреационная & 7 & 0,98 & 0,02 & 8 & 0,06 & 0,88 & 0,13 \\
\hline
\end{tabular}

*B промышленной и садово-огородной зонах-биотопах учет собак на контрольном участке не проводили (см. «Материалы и методы»).

Таблица 3. Результаты учёта численности популяции свободноживущих собак г. Омска

\begin{tabular}{|c|c|c|c|c|c|c|}
\hline \multirow[t]{2}{*}{ Зона-биотоп } & \multirow{2}{*}{$\begin{array}{c}\text { Число } \\
\text { особей вне } \\
\text { контрольного } \\
\text { участка, ос. }\end{array}$} & \multicolumn{2}{|c|}{$\begin{array}{c}\text { Скорректированное } \\
\text { число особей } \\
\text { вне контрольного } \\
\text { участка, ос. }\end{array}$} & \multicolumn{2}{|c|}{$\begin{array}{c}\text { Средняя взвешенная } \\
\text { плотность, ос/км² }\end{array}$} & \multirow{2}{*}{$\begin{array}{c}\text { Общая } \\
\text { численность, } \\
\text { ос. }\end{array}$} \\
\hline & & $\widetilde{N}_{w}$ & $e\left(\widetilde{N}_{w}\right)$ & $\widetilde{D}$ & $e(\widetilde{D})$ & \\
\hline $\begin{array}{l}\text { Жилая } \\
\text { одноэтажная }\end{array}$ & 157 & 336 & 0,18 & 116,2 & 0,18 & 4313 \\
\hline $\begin{array}{l}\text { Жилая } \\
\text { многоэтажная }\end{array}$ & 231 & 296 & 0,10 & 76,7 & 0,16 & 3570 \\
\hline Промышленная & 145 & - & - & $126,2^{*}$ & 0,21 & 3300 \\
\hline Садово-огородная & 73 & - & - & 43,3 & 0,33 & 2850 \\
\hline Рекреационная & 33 & 38 & 0,15 & 9,4 & 0,08 & 48 \\
\hline Всего & 639 & & & 69,23 & 0,11 & 14081 \\
\hline
\end{tabular}

* - средневзвешенная плотность в промышленной зоне-биотопе экстраполировалась только на дробную часть зоныбиотопа (см. «Материалы и методы»).

ной части промышленной зоны-биотопа обусловлено наличием большого количества мест, пригодных для укрытия и выведения потомства. Кроме того, здесь в сравнительно большом количестве имеются различного рода предприятия общепита, а также хорошо развито так называемое опекунство со стороны сотрудников предприятий, сторожей, работников столовых, которые подкармливают местных собак.
Сравнительно низкая плотность популяции зафиксирована в садово-огородной зоне-биотопе - 43,3 ос/км². Собаки данной территории - это, как правило, брошенные или оставленные владельческие собаки. Места их дневок приурочены к какому-либо садовому участку (зачастую заброшенному или редко посещаемому людьми) или к сторожке. Низкая плотность указывает и на слабый трофический потенциал территорий: сады не яв- 
ляются жилыми районами, продуктовых магазинов и рынков нет, продукты привозные. Кроме того, посещение данной зоны-биотопа людьми носит сезонный характер, и в зимний период в садоводческих кооперативах остаются только сторожа. Изучение сезонной динамики численности собак в задачи данной работы не входило, но, со слов сторожей садоводческих кооперативов, можно судить о том, что в зимний период собак в садовоогородной зоне-биотопе становится меньше.

Оценка плотности населения в данной зоне-биотопе сопровождается большим значением статистической ошибки (табл. 3). Это вызвано большой дисперсией значений плотности, что, в свою очередь, может быть связано с неоднородностью выделенной зоныбиотопа. Для более точной оценки плотности населения собак в садово-огородной зонебиотопе целесообразно дифференцировать садовые участки, непосредственно примыкающие к жилым и промышленным зонамбиотопам, а также садовые участки, расположенные по окраинам города и окруженные остатками естественных экосистем. На этих территориях плотность населения свободноживущих собак отличается; при объединении их в одну зону-биотоп увеличивается ее дисперсия и, соответственно, статистическая ошибка.
В рекреационной зоне-биотопе зафиксировано минимальное значение средней плотности населения - 9,4 ос/км². Это обусловлено особенностями использования данных территорий человеком. Все обнаруженные здесь собаки приурочены к редко расположенным источникам пищи (ларьки, киоски, сторожки, санатории), остальные территории парков, скверов (не имеющие антропических источников питания) не заселены.

При выборочных учетах животных достаточно большие значения относительной статистической ошибки встречаются часто (Челинцев, 2000), поэтому помимо точечных оценок численности нами были произведены интервальные оценки (табл. 4).

\section{Половая структура}

В целом в половой структуре популяции отмечено небольшое, но значимое $(\mathrm{p}=0,008)$ преобладание кобелей (табл. 5). Однако по всем зонам-биотопам кроме зоны жилой одноэтажной застройки среди половозрелых особей соотношение полов составляет примерно 1:1, наблюдаемые отклонения статистически не значимы. В зоне-биотопе жилой одноэтажной застройки в половой структуре достоверно преобладали кобели ( $\mathrm{p}=0,011)$. Именно большое количество кобелей в зонебиотопе жилой одноэтажной застройки и

Таблица 4. Интервальная оценка численности свободноживущих собак популяции г. Омска $(\mathrm{P}=95$ \%)

\begin{tabular}{|l|c|c|c|c|c|}
\hline \multirow{2}{*}{ Зона-биотоп } & \multirow{2}{*}{ Численность, ос. } & \multicolumn{2}{|c|}{ Односторонний } & \multicolumn{3}{|c|}{ Двусторонний } \\
\cline { 3 - 6 } & & дижниельный & верхний & нижний & верхний \\
\hline Жилая одноэтажная & 4313 & 3167 & 5689 & 2991 & 6024 \\
\hline Жилая многоэтажная & 3570 & 2710 & 4584 & 2575 & 4825 \\
\hline Промышленная & 3300 & 2298 & 4539 & 2150 & 4851 \\
\hline Садово-огородная & 2850 & 1597 & 4586 & 1441 & 5082 \\
\hline Рекреационная & 48 & 42 & 55 & 41 & 56 \\
\hline Всего & 14081 & 11693 & 16755 & 11289 & 17353 \\
\hline
\end{tabular}


Таблица 5. Половозрастная структура популяции свободноживущих собак г. Омска, 2005 г.

\begin{tabular}{|c|c|c|c|c|c|c|}
\hline \multirow{4}{*}{ Зона-биотоп } & \multicolumn{6}{|c|}{ Количество } \\
\hline & \multicolumn{4}{|c|}{ взрослые (половозрелые) } & \multirow{3}{*}{$\begin{array}{c}\text { щенки, } \\
\text { ос. }\end{array}$} & \multirow{3}{*}{ Всего, ос } \\
\hline & \multicolumn{2}{|c|}{ кобели } & \multicolumn{2}{|c|}{ суки } & & \\
\hline & Oc. & $\%$ & Oc. & $\%$ & & \\
\hline Жилая одноэтажная & 81 & $61,4 \pm 4,2$ & 51 & $38,6 \pm 4,2$ & 19 & 151 \\
\hline Жилая многоэтажная & 119 & $53,6 \pm 3,3$ & 103 & $46,4 \pm 3,3$ & 35 & 257 \\
\hline Промышленная & 50 & $55,6 \pm 5,2$ & 40 & $44,4 \pm 5,2$ & 55 & 145 \\
\hline Садово-огородная & 31 & $53,4 \pm 6,5$ & 27 & $46,6 \pm 6,5$ & 15 & 73 \\
\hline Рекреационная & 14 & $53,8 \pm 9,8$ & 12 & $46,2 \pm 9,8$ & 7 & 33 \\
\hline Итого & 295 & $55,9 \pm 2,2$ & 233 & $44,1 \pm 2,2$ & 131 & 659 \\
\hline
\end{tabular}

привело к смещению соотношения полов во всей популяции.

\section{Размер выводка}

Всего было осмотрено 78 выводков со щенками в возрасте 1-1,5 мес., минимальный размер выводка - один щенок, максимальный - 10, средний размер выводка в популяции за пять лет наблюдений составил 4,3 особи (табл. 6).

\section{Обсуждение}

Полученные нами значения плотности популяции значимо превышают данные по г. Петрозаводску (Ивантер, Седова, 2008), г. Москве (Поярков и др., 2011), г. Пензе (Золина, 2011), а также превышают данные учётов по г. Омску, проведённых Е.С. Березиной в 1999 г. (Березина, 2002). Во многом разница в результатах объясняется выбором единицы учёта: во всех указанных работах авторы изучали бесхозяйных собак, мы же учитываем всех свободноживущих собак, в том числе бесхозяйных и собак полувольного содержания.

Полученные нами данные по половой структуре хорошо коррелируют с результатами исследований по г. Москве и г. Петрозаводску, в которых отношение кобелей к сукам составило 1,19:1 (Поярков и др., 2011) и 1:1 (Седова, 2007) соответственно. По нашим данным, кобели численно преобладали только в зоне-биотопе жилой одноэтажной застройки. Это объясняется тем, что в этой зоне много собак полувольного содержания, а их пол во многом определяется предпочтениями хозяев.

Информацию о размере выводков нам удалось найти только для одичавших собак (feral dogs): среднее количество щенков в выводке для них составило, по разным данным, 3,6 (Boitani, Ciucci, 1995) и 5,5 особей (Macdonald, Carr, 1995), что соответствует полученным нами результатам. Однако важно отметить, что наши данные характеризуют лишь количество щенков в выводках, доживших до 1 мес., и не учитывают гибель щенков в раннем возрасте.

Отдельно хотелось бы обратить внимание на относительное количество щенков в промышленной зоне-биотопе, где их значительно больше, чем в других зонах-биотопах (табл. 5). Возможной причиной этого могут быть особенности среды в промзоне: в ней много мест для укрытия и для выведения потомства, это может привлекать беременных сук с близлежащих территорий для обустройства логов и выведения потомства. 
Таблица 6. Размеры выводков щенков в возрасте 1-1,5 мес. свободноживущих собак популяции г. Омска

\begin{tabular}{|c|c|c|c|c|}
\hline Год & $\begin{array}{c}\text { Осмотрено } \\
\text { выводков }\end{array}$ & Всего щенков & Пределы & Среднее \\
\hline 2002 & 11 & 37 & $2-8$ & $3,4 \pm 0,5$ \\
\hline 2003 & 12 & 42 & $2-8$ & $3,5 \pm 0,5$ \\
\hline 2004 & 26 & 118 & $1-10$ & $4,5 \pm 0,5$ \\
\hline 2005 & 22 & 92 & $2-8$ & $4,2 \pm 0,4$ \\
\hline 2006 & 7 & 45 & $3-9$ & $6,4 \pm 0,9$ \\
\hline Всего & 78 & 334 & $1-10$ & $4,3 \pm 0,3$ \\
\hline
\end{tabular}

\section{Заключение}

В ходе проведённого исследования были получены сведения, которые можно использовать при планировании мероприятий по регулированию численности бесхозяйных собак. Было установлено, что плотность популяции свободноживущих собак г. Омска зависит от типа застройки среды и составляет в среднем 69 ос/км². Максимальная плотность популяции зафиксирована в промышленной зоне- биотопе и зоне-биотопе одноэтажной жилой застройки, минимальная - в рекреационной. Общая численность свободноживущих собак в г. Омске в 2005 г. составила примерно 14 тыс. особей. Во всех зонах-биотопах, кроме жилой одноэтажной, соотношение полов равно примерно 1:1, в жилой одноэтажной зоне численно преобладают кобели. Средняя численность выводка свободноживущих собак $-4,3$ особи.

\section{Список литературы}

1. Березина Е.С. (2002) Экология собак городских популяций. Классификация экологических групп, численность, популяционная структура, коммуникации (на модели города Омска и области). Ветеринарная патология 1: 132-135.

2. Березина Е.С. (2012) Популяционная структура, особенности поведения и морфологии свободноживущих собак и кошек и значение этих животных в эпизоотических и эпидемических процессах при бешенстве, токсокарозе и токсоплазмозе: автореф. дис. ... д-ра биол. наук, Омск, 42 с.

3. Боголюбский С.Н. (1959) Происхождение и преобразование домашних животных. М.: Советская наука, 549 с.

4. Золина Н.Ф. (2011) Особенности экологии популяций бездомных собак в городе Пензе. Известия Пензенского государственного университета им. В.Г. Белинского. Естественные науки 25: 195-198.

5. Ивантер Э.В., Седова Н.А. (2008) Экологический мониторинг группировок бездомных собак (на примере г. Петрозаводска). Экология 2: 116-121.

6. Макенов М.Т. (2007) Экологическая характеристика популяций синантропных собакпарий: автореф. дис. ... канд. биол. наук, Омск, 16 с.

7. Макенов М.Т., Михайлова О.А. (2013) Укусы людей собаками: общая характеристика. Журнал Сибирского федерального университета. Серия: Биология 6 (1): 32-43. 
8. Поярков А.Д., Верещагин А.О., Богомолов П.Л. (2011) Исследование популяции бездомных собак (Canis familiaris) на территории Москвы. Сообщение 2. Зоологический журнал 90 (6): 724-732.

9. Рахманов А.И. (2002) Проблема бродячих собак в городах. Ветеринарная патология 1: 136140.

10. Седова Н.А. (2007) Экологический анализ населения бездомных собак в городах Карелии: автореф. дис. ... канд. биол. наук, Петрозаводск, 19 с.

11. Челинцев Н.Г. (2000) Математические основы учёта животных. Москва: Центроохотконтроль, $431 \mathrm{c.}$

12. Boitani L., Ciucci P. (1995) Comparative social ecology of feral dogs and wolves. Ethology Ecology and Evolution 7: 49-72.

13. Macdonald D.W., Carr G.M. (1995) Variation in dog society: between resource dispersion and social flux. In: J. Serpell (ed.) The Domestic dog: Its evolution, behaviour and interactions with people. Cambridge: Cambridge University Press, p. 199-217. 